\title{
Materiais Diversos Um privilégio para todos
}

\section{Ana Pais}

De repente fica tudo preto

de gente,

de Marcelo Evelin,

Demolition inc., 2012

(Andrez Lean Ghizze)

fot. Joana Patita.

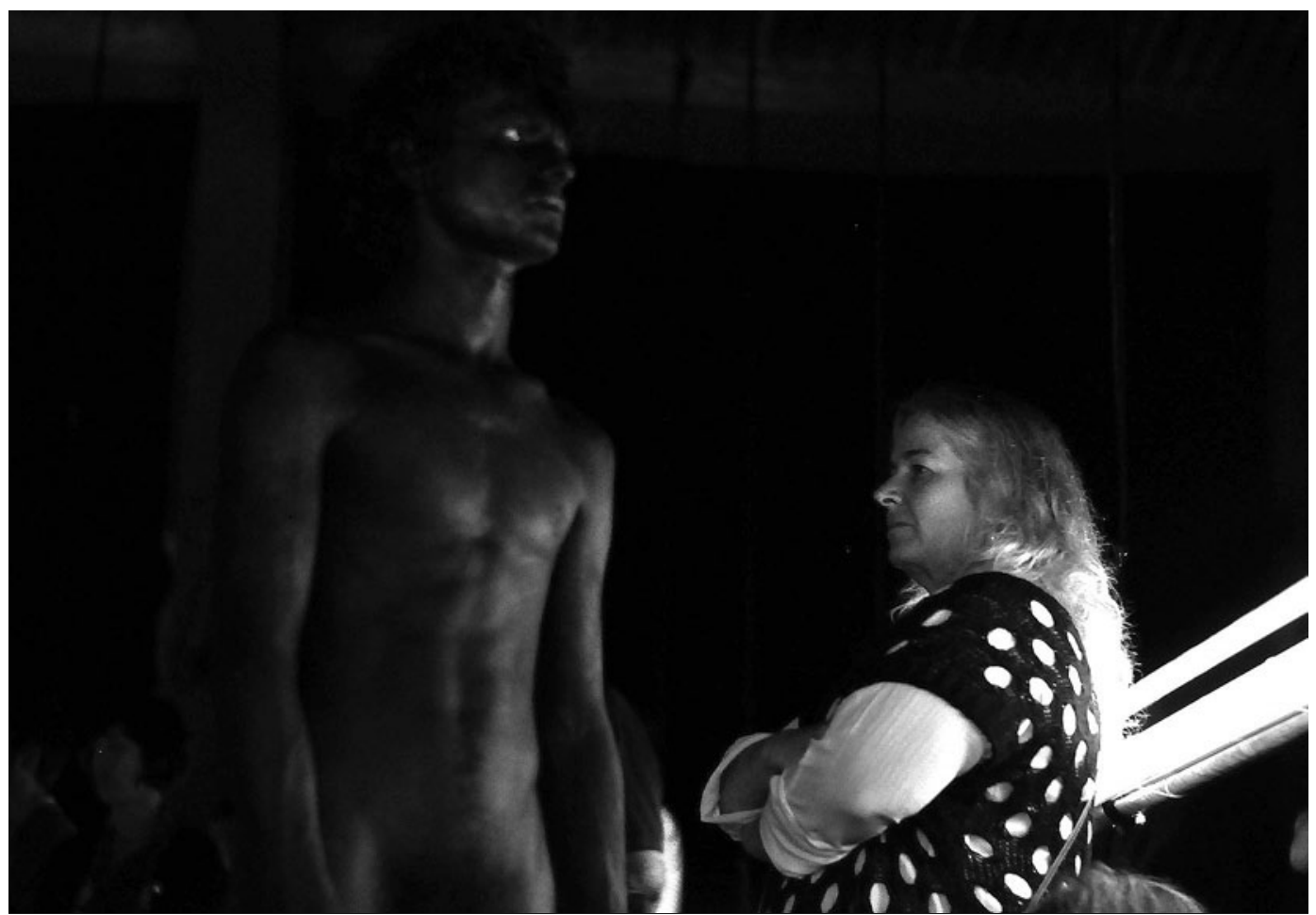

Título: Não sou só eu aqui. Direcção Artística: Cláudia Gaiolas e Rita Rio. Produção: Materiais Diversos. Local e data de apresentação: Cineteatro São Pedro, Alcanena, 18 Setembro 2014.

Título: De repente fica tudo preto de gente. Coreografia: Marcelo Evelin / Demolition Inc. Co-produção: Festival Panorama, Kyoto Experiment com apoio Saison Foundation, Kunstenfestivaldesarts. Local e data de apresentação: Fábrica de Cultura, Minde, 19 Setembro 2014

Título: Vontade de ter vontade. Coreografia: Cláudia Dias. Produção: SUMO/Sofia Campos. Local e data de apresentação: Fábrica de Cultura, Minde, 20 de Setembro 2014.

Privilégio é a palavra que melhor define a minha experiência na sexta edição do festival Materiais Diversos, como espectadora e como formadora de um grupo de jovens durante o primeiro fim-de-semana. Ser privilegiado é ter direito ou gozar de vantagem especial relativamente a outros, que não o têm. Na sua etimologia latina, esse direito privado é garantido pela lei, uma lei de exclusão. Porém, o festival promove exactamente o contrário: oferecer a todos, sem distinção, condições privilegiadas de contacto com a arte. Cria uma lei de inclusão.

Os privilégios foram vários. Em primeiro lugar, o contacto estabelecido entre as comunidades locais e os artistas não se releva apenas da rede de municipios que suporta o festival (Alcanena, Cartaxo e Torres Novas), mas traduz-se numa convivência invulgar gerada pelo facto de os artistas ficarem alojados nas casas da população. Em segundo lugar, a proximidade inigualável que a sua pequena escala proporciona aos espectadores e participantes em espaços conviviais. Em terceiro lugar, a ligação única entre o local, a Europa e o mundo, que traz a pequenas comunidades uma programação internacional forte aposta desta edição.

Qualquer um destes factores reflecte-se igualmente nas escolhas da programação. A vontade de promover 


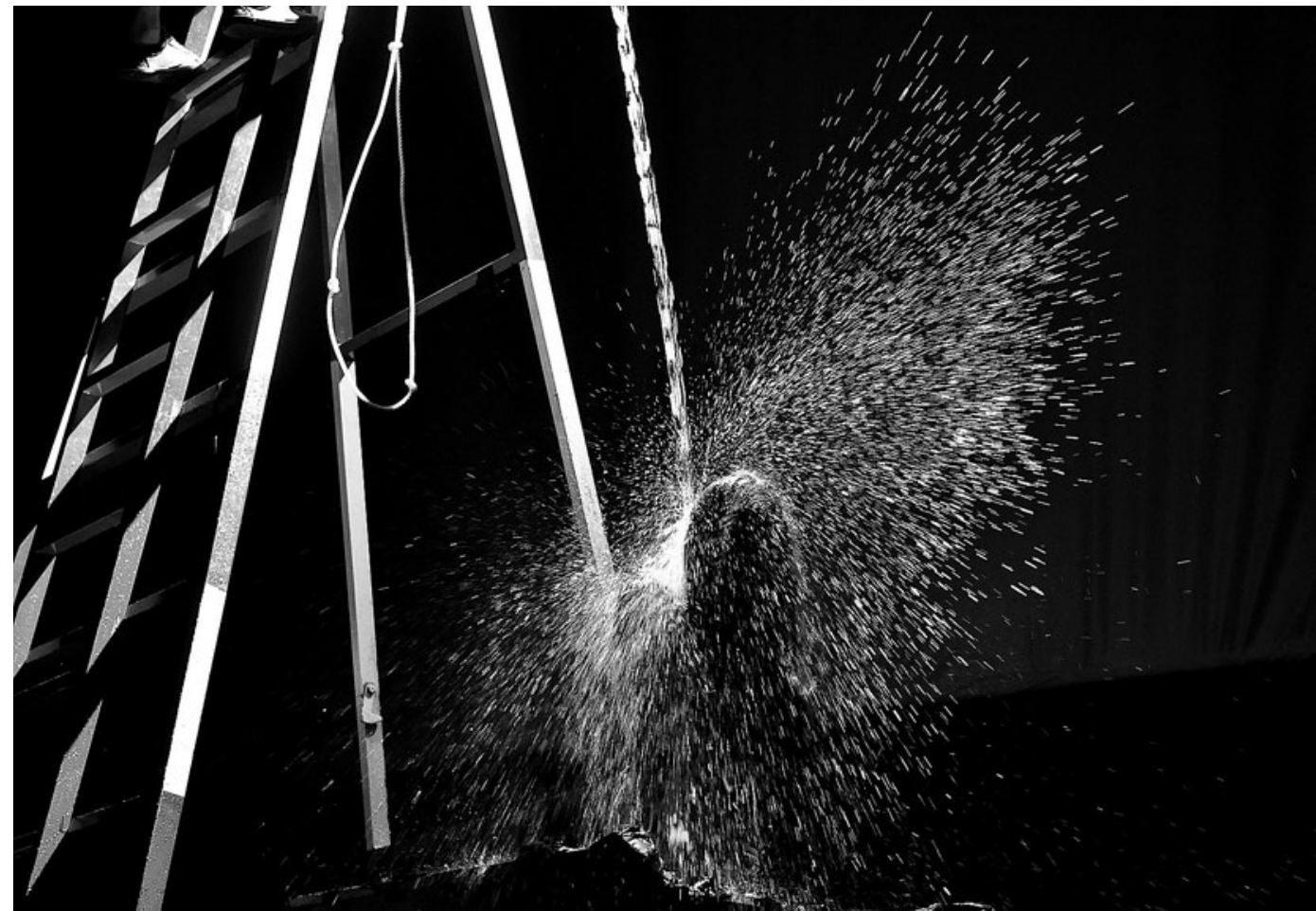

Não sou só eu aqui de Cláudia Gaiolas Et Rita Rio de Sousa, 2014 (Joana Moita), fot. Joana Patita.

formas de contacto com o local surge desde logo no espectáculo de abertura, sobre o trabalho dos curtumes, indústria tradicionalmente instalada na zona de Alcanena: Não sou só eu aqui (2014), de Cláudia Gaiolas e Rita Rio. A questão da proximidade, designadamente com o público, é um traço distintivo da proposta De repente fica tudo preto de gente (2012), do coreógrafo brasileiro Marcelo Evelin. A relação entre o local e o internacional colocase de forma programática no espectáculo de Cláudia Dias, Vontade de ter vontade (2011).

\section{Não sou só eu aqui}

Construído com os operários da fábrica de curtumes, Não sou só eu aqui surge de um convite de Tiago Guedes a Cláudia Gaiolas e Rita Rio para criarem um espectáculo a partir daquele universo. Abrindo o festival perante uma plateia de familiares, amigos e agentes culturais, este espectáculo constitui-se por quadros cujos protagonistas são os próprios operários, partilhando o seu quotidiano, expectativas e ritmos. A primeira cena é marcante. Num espaço despido, com uns tijolos ao fundo, uma escada do lado esquerdo da boca de cena serve de roldana para um baptismo de palco. Um a um, homens e mulheres de idades diferentes entram num tanque colocado junto ao escadote e deixam-se levar, literalmente, com um balde de água em cima. Hábito rotineiro de um operário de curtumes depois de acabar o trabalho, o banho evoca a presença da água na fábrica e transforma o lavar das peles - animais e humanas - num momento esteticamente bem desenhado e de alto impacto afectivo. A surpresa e a admiração, potenciada por esta exposição pública, abre caminho para um discurso de partilha, desvelando formas de vida ritmadas por uma rotina de sons de máquinas e cheiros das peles.

Um elemento importante da construção dramatúrgica é o reforço do lugar de enunciação dos trabalhadores, em detrimento de uma construção cénica que fale por eles. Declara-se o lugar de onde se fala, por exemplo, com a expressão repetida "Eu daqui vejo", numa cena do início do espectáculo em que cada operário vem à frente enumerar quem vê (colegas) do sítio onde trabalha e, mais adiante, o que vê (máquinas). Não há nenhuma moral, nenhuma celebração da vida fabril, nenhuma idealização, mas sim uma criação colaborativa que os participantes, 


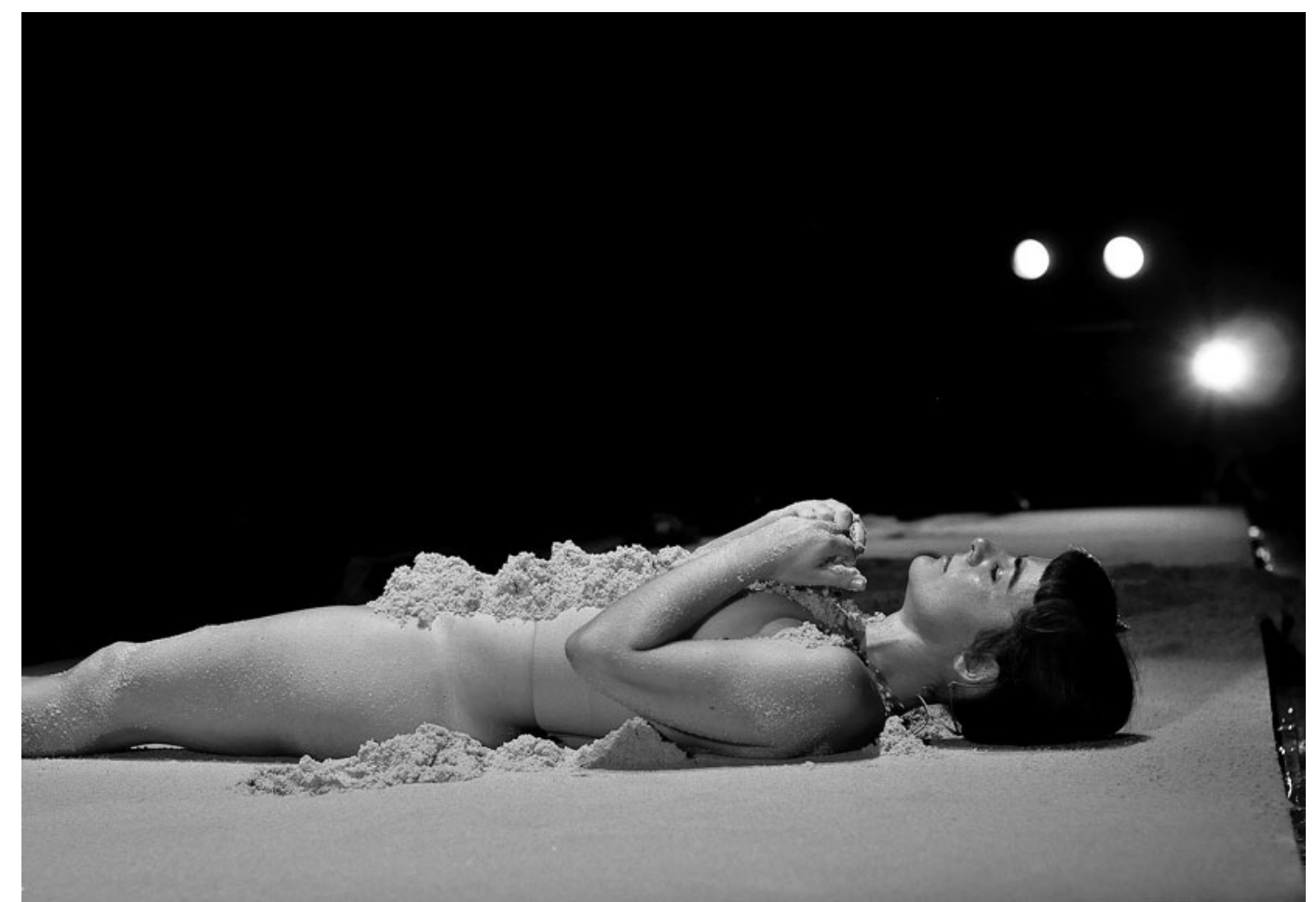

segundo testemunhos dos próprios no final do espectáculo afirmaram como uma experiência positiva, embora não necessariamente transformadora. Eu acrescentaria que essa foi uma experiência privilegiada que, em si, constitui a transformação: da partilha da vida em cena.

\section{De repente fica tudo preto de gente}

A expressão brasileira "tudo preto de gente" aplica-se quando, subitamente, um aglomerado de gente se forma para ver uma escaramuça na rua ou um acidente de carro, por exemplo. A cor preta sugere aqui uma totalidade, uma impossibilidade de indistinção dos elementos - da gente. É justamente um trabalho sobre a invisibilidade, que impossibilita a diferenciação, a aglomeração que potencia o contacto entre as peles de qualquer cor - a contaminação, olhar e tocar um outro que não se conhece -, que esta proposta promove. E ele depende da proximidade entre os corpos, entre os bailarinos e os espectadores.

0 público é convidado a partilhar o mesmo espaço ocupado pelos bailarinos. Lembrando um ringue de boxe - e todas as suas violentas conotações da luta corpo a corpo -, os espectadores entram para uma cena delimitada por luzes fluorescentes. Lá dentro já estão os bailarinos, corpos nus e integralmente pintados de preto. Existe a opção de ficar do lado de fora, mas a proposta incita claramente a uma negociação do espaço com os performers, que se movem em direç̧ões inesperadas e ritmos diferenciados, formando figuras de conjunto, tanto dóceis e sensuais quanto violentas e explosivas. Não é possivel ficar longe dos bailarinos, nem tão pouco manter a roupa imaculada - contaminação cromática do outro que se move e nos força a mover com ele. Elemento estrutural desta proposta, a proximidade gera afectos de repulsa e de atracção, defensivos e curiosos, desafiadores ou conformistas. A gestão destes afectos é a responsabilidade participativa do espectador.

\section{Vontade de ter vontade}

No espaço da Fábrica das Artes, em Minde, Cláudia Dias interrogou noções de identidade, de opções de um caminho e construção, bem como de pertença particularmente pertinentes no contexto político e económico actual. A partir do local pensa-se o global, especificamente, a relação de Portugal no espaço europeu, do que foi feito e do que falta fazer, das possibilidades e constrangimentos que essa relação oferece ao nivel das acções e escolhas que se apresentam a cada um de nós, local e globalmente.

Cláudia Dias atravessa um rectângulo de areia numa caminhada de perguntas e reflexões, durante a qual os figurinos (um deles, a nudez), que evocam cores de bandeiras de paises, são despidos metodicamente para voltarem a ser vestidos, no regresso ao ponto de partida. Este percurso marcado e moldado pelo corpo da intérprete e coreógrafa será apagado, alisando a areia, mas nunca recupera a imagem do início. Tal como caminhar na areia, pensar deixa vestígios irreparáveis. A impermanência da vida - tudo se transforma e é transformado por nós - e a passagem do tempo - igualmente implacável - movemnos a reflectir sobre o que norteia a nossa "vontade". Esta vontade não é apenas pessoal, mas histórica e cultural. 0 espectáculo convoca aspectos geopolíticos da história e da cultura portuguesa, como o colonialismo ou a construção da identidade europeia, para uma reflexão sobre as consequências da direcção que tomamos e das escolhas que fazemos. Tal como na construção de um espectáculo, também na construção de um país tudo são opções com repercussões, pessoais e políticas, para a vida e o país que temos vontade de ser. 